\title{
Effects of CdS Buffer Layers on Photoluminescence Properties of $\mathrm{Cu}_{2} \mathrm{ZnSnS}_{4}$ Solar Cells
}

\author{
A. Le Donne, ${ }^{1}$ S. Marchionna, $^{2}$ P. Garattini, ${ }^{1}$ R. A. Mereu, ${ }^{1}$ M. Acciarri, ${ }^{1}$ and S. Binetti ${ }^{1}$ \\ ${ }^{1}$ Department of Materials Science and Milano-Bicocca Solar Energy Research Center (MIB-SOLAR), University of Milano-Bicocca, \\ Via Cozzi 55, 20125 Milan, Italy \\ ${ }^{2}$ RSE S.p.A., Via R. Rubattino 54, 20134 Milan, Italy
}

Correspondence should be addressed to A. Le Donne; alessia.ledonne@mater.unimib.it

Received 17 December 2014; Revised 16 February 2015; Accepted 19 February 2015

Academic Editor: Yanfa Yan

Copyright (C 2015 A. Le Donne et al. This is an open access article distributed under the Creative Commons Attribution License, which permits unrestricted use, distribution, and reproduction in any medium, provided the original work is properly cited.

$\mathrm{Cu}_{2} \mathrm{ZnSnS}_{4}$ (CZTS) absorber layers grown by sputtering were investigated by photoluminescence before and after the chemical bath deposition of CdS in order to evaluate the possible passivation of point defects by $\mathrm{Cd}$ atoms at the absorber/buffer layer interface. According to the literature, a broad emission around $1.21 \mathrm{eV}$ was observed at low temperature under above bandgap excitation of the as-grown CZTS samples. Broad bands at $1.075 \mathrm{eV}$ and $0.85 \mathrm{eV}$ were detected for the first time under below bandgap excitation of the as-grown CZTS samples at low temperature, which were explained in terms of radiative transitions involving point defect-related levels determined in the literature by first-principles calculations. The emissions observed in the as-grown samples were monitored by both above and below bandgap excitations also in standard CZTS solar cells produced on the same layers. The obtained results suggest that, as in the case of $\mathrm{Cu}(\mathrm{In}, \mathrm{Ga}) \mathrm{Se}_{2}, \mathrm{Cd}$ atoms passivate point defects at the absorber/buffer layer interface also in CZTS.

\section{Introduction}

It is widely known that the most promising absorbers for thin film photovoltaics (PV), namely, CdTe, $\mathrm{CuInSe}_{2}$ (CIS), $\mathrm{Cu}(\mathrm{In}, \mathrm{Ga}) \mathrm{Se}_{2}$ (CIGS), $\mathrm{Cu}_{2} \mathrm{ZnSnS}_{4}$ (CZTS), and $\mathrm{Cu}_{2} \mathrm{ZnSn}(\mathrm{S}$, $\mathrm{Se})_{4}$ (CZTSSe), show intrinsic p-type conductivity related to the presence of point defect-related levels in the bandgap. Thin film solar cells based on them can therefore adopt the same device structure, employing CdS from chemical bath deposition (CBD) as buffer layer. In spite of the fact that the highest efficiencies of thin film solar cells were obtained using well-established CdS buffer layers [1], CdS preparation by CBD involves serious environmental problems due to the large amount of cadmium-containing waste produced during the deposition process. Cd-free alternative buffer materials have been therefore actively investigated, mainly for CIGS based PV [2]. Despite the strong efforts in this field, up to now no alternative buffer layers providing efficiency comparable to those related to CdS were produced. Most probably this is related to the beneficial effects of the intermixing occurring at the CdS/CIGS interface. First of all, $\mathrm{Cu}$-vacancies in the $\mathrm{Cu}$-poor surface of the CIGS absorber layer are considerably passivated by $\mathrm{Cd}$ atoms [3-6]. Furthermore, Ga and In substitutional defects on the buffer cation site act as favourable shallow donors, which can enhance the CdS n-type conductivity, supplementing the donor doping of the CIGS absorber with $\mathrm{Cd}_{\mathrm{Cu}}$ and facilitating type inversion at the CdS/CIGS interface [7].

$\mathrm{ZnS}$ from $\mathrm{CBD}$ and $\mathrm{Zn}(\mathrm{O}, \mathrm{S})$ from Atomic Layer Deposition were recently considered as alternative buffer layers for CZTS based PV [8-10]; however, the efficiencies are not yet comparable with those typical of CdS from CBD, as in the case of CIGS. The best performance was obtained by applying a double $\mathrm{In}_{2} \mathrm{~S}_{3} / \mathrm{CdS}$ emitter to CZTSSe [11], which merges the advantages of both buffer layers (i.e., the favourable band alignment typical of CdS on CZTS-CZTSSe [12] and the In capability to form $\operatorname{In}_{\mathrm{Cd}}$ in CdS and $\mathrm{In}_{\mathrm{Sn}}$ in CZTSSe [11]) but still involves Cd.

In this work, a detailed analysis of the defect-related radiative recombinations in CZTS thin films with compositional ratios in the range associated with high efficiency devices is reported. Such an analysis was carried out before and after the CBD of CdS in order to evaluate the possible passivation of point defects by Cd atoms at the CdS/CZTS interface. As 
a matter of fact, experimental evidences of the $\mathrm{V}_{\mathrm{Cu}}$ passivation by $\mathrm{Cd}$ atoms at the CdS/CIGS interface were obtained by comparison of the photoluminescence (PL) features of CIGS layers and CdS/CIGS heterojunctions $[13,14]$, so the same can be expected in the case of CdS/CZTS solar cells. Both above and below bandgap excited PL were considered, which allowed the identification of several emissions associated with different recombination paths at the CZTS surface. Excitation power and temperature dependent PL studies were used to unravel the recombination mechanisms responsible for the observed radiative emissions.

\section{Material and Methods}

CZTS samples examined in this work were grown by sulphurization of stacked metal precursors, as described in detail in [15]. The metal precursors were deposited on $2.5 \times 5 \mathrm{~cm}^{2}$ Mo coated soda lime glasses (SLG) at room temperature by $\mathrm{RF}$ sputtering with precursor sequence SLG/Mo/Sn/Cu/Zn, in order to obtain the $\mathrm{Cu}$-poor/Zn-rich stoichiometry typical of CZTS PV devices with $\eta>3 \%$ [16]. CZTS films approximately $2 \mu \mathrm{m}$ thick were finally formed by thermal treatment of the metal precursors in a mixed argon $\left(30 \mathrm{~cm}^{3} / \mathrm{min}\right.$ flux $)$ and elemental sulphur atmosphere at $580^{\circ} \mathrm{C}$ for $60 \mathrm{~min}$. As the samples were grown to obtain $\mathrm{Zn}$-rich conditions [15], an etching procedure in diluted $\mathrm{HCl}$ (aqueous solution $5 \% \mathrm{v} / \mathrm{v}$ at $75^{\circ} \mathrm{C}$ for $300 \mathrm{sec}$ [17]) was performed on the as-grown layers in order to remove superficial $\mathrm{ZnS}$. As shown in [15], the whole procedure led to CdS/CZTS heterojunctions with $4 \%$ efficiency (without antireflection coating).

Both morphology and chemical composition of the sulphured CZTS layers were investigated with a Tescan VEGA TS5136XM scanning electron microscope (SEM) equipped for energy-dispersive spectroscopy (EDS). The operating voltage used for all the SEM images is $20 \mathrm{kV}$, while EDS analyses were performed with a EDAX Genesis 4000 XMS Imaging 60 under the following conditions: operating voltage $20 \mathrm{kV}$, probe current $190 \mathrm{pA}$, probe size $230 \mathrm{~nm}$, working distance $23 \mathrm{~mm}$, and calibration with 53 Minerals Standard Mount MINM25-53.

The crystal structure of the sulphured CZTS films was examined by X-ray diffraction (XRD) and Raman spectroscopy. X-ray powder diffraction patterns were collected by a Bruker D8 advance diffractometer $(\mathrm{CuK} \alpha$ radiation, $40 \mathrm{kV}$, $30 \mathrm{~mA}$ ) with theta/theta geometry and secondary curved beam monochromator. The scan step and step time were $0.020^{\circ}$ and $3 \mathrm{sec}$, respectively. Raman measurements were carried out at room temperature with a Jasco Ventuno microRaman system in backscattering configuration, equipped with a Peltier-cooled charge-coupled device camera (operating temperature $-50^{\circ} \mathrm{C}$ ) and a $\mathrm{He}-\mathrm{Ne}$ laser (excitation wavelength of $632.8 \mathrm{~nm}$ ). Proper laser power density was chosen to generate the best signal-to-noise ratio without broadening or shifting the Raman peaks due to local heating. All the samples have been inspected by Raman spectroscopy in height uniformly distributed points in order to evaluate their in-plane homogeneity.

The sulphured CZTS layers were inspected by photoluminescence before and after the chemical bath deposition of a thin $(70 \mathrm{~nm}) \mathrm{CdS}$ layer. In particular, the samples were immersed in a Cd acetate $\left(\mathrm{Cd}\left(\mathrm{CH}_{3} \mathrm{COO}\right)_{2}\right)$ aqueous solution mixed with an ammonium hydroxide $\left(\mathrm{NH}_{4} \mathrm{OH}\right)$ aqueous solution and heated in a water bath at $75^{\circ} \mathrm{C}$. Thiourea $\mathrm{SC}\left(\mathrm{NH}_{2}\right)_{2}$ aqueous solution is then added therein to begin the actual $\mathrm{CdS}$ deposition. The whole solution is kept at $75^{\circ} \mathrm{C}$ under slow stirring for $11.5 \mathrm{~min}$ until the desired film thickness is reached. The samples are then washed with bidistilled water and dried in air at room temperature.

Photoluminescence spectra of all CZTS samples have been studied in the 775-1700 $\mathrm{nm}$ and $20-300 \mathrm{~K}$ ranges with above bandgap excitation $\left(\lambda_{\text {exc }}=402 \mathrm{~nm}\right)$ and in the 1100$1700 \mathrm{~nm}$ and $20-80 \mathrm{~K}$ ranges with below bandgap excitation $\left(\lambda_{\text {exc }}=1064 \mathrm{~nm}\right)$. A cooling system consisting of rotary, turbomolecular, and cryogenic pumps equipped with a resistance heater was used to perform PL measurements in the temperature range between 20 and $300 \mathrm{~K}$. Variations in the PL spectra have been studied as a function of excitation laser intensity for both above and below bandgap excitations. All PL measurements were performed with a spectral resolution of $2 \mathrm{~nm}$ using a standard lock-in technique in conjunction with a single grating monochromator and a short wavelength enhanced InGaAs detector with maximum responsivity at $1540 \mathrm{~nm}$.

Finally, the bandgap of the examined CZTS samples has been monitored by measuring the external quantum efficiency (EQE) of solar cells based on them. After the CBD of $\mathrm{CdS}$, an intrinsic $\mathrm{ZnO}$ buffer layer $80 \mathrm{~nm}$ thick was deposited by RF sputtering. Then, a transparent conductive oxide layer consisting of $350 \mathrm{~nm}$ Al-doped $\mathrm{ZnO}$ (AZO) was grown by DC pulsed $(2 \mathrm{kHz})$ sputtering. The cell was finally completed by evaporating an $\mathrm{Al}$ contact grid. EQE measurements were obtained with a SpeQuest quantum efficiency system. The spectral response curves of the solar cells were taken from $350 \mathrm{~nm}$ to $1100 \mathrm{~nm}$ with a $10 \mathrm{~nm}$ wavelength increment. The EQE spectrum was then calculated as the ratio between the spectral response data and the incident light spectrum, measured with a reference photodiode (ThorLabs S120VC).

\section{Results and Discussion}

First of all, EDS analyses performed on the as-grown layers etched with $\mathrm{HCl}$ [17] confirmed that the desired $\mathrm{Cu}$-poor/Znrich conditions were obtained. In particular, the mean atomic concentrations of $\mathrm{Cu}, \mathrm{Zn}, \mathrm{Sn}$, and $\mathrm{S}$ were proven to be $16 \%$ at., $25 \%$ at., $11 \%$ at., and $48 \%$ at., respectively. The SEM micrographs reported in Figures 1(a) (plan view) and 1(b) (cross section) show the compactness and homogeneous surface morphology with large grains $(1-1.5 \mu \mathrm{m})$ typical of the as-grown layers etched with $\mathrm{HCl}$ [17], which are in agreement with those previously reported in the literature [18-20].

$\mathrm{XRD}$ analyses performed on the as-grown layers etched with $\mathrm{HCl}$ [17] (see Figure 2(a)) confirmed the formation of the CZTS phase with large grain dimensions, as proven by the sharp diffraction peaks, in agreement with the SEM estimate. Owing to the very similar crystal structure of CZTS and of some of its most common secondary phases (i.e., $\mathrm{ZnS}$ and $\mathrm{Cu}_{2} \mathrm{SnS}_{3}$ ) [21], Raman measurements are required to demonstrate their presence, as no evidence can be inferred from 


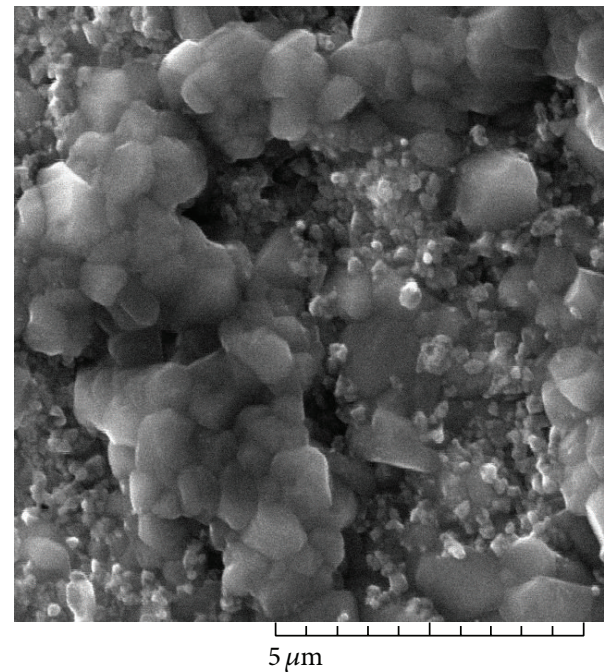

(a)

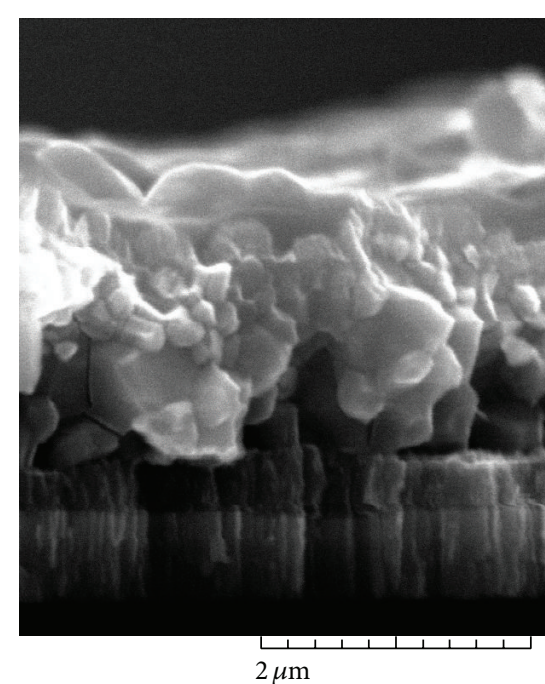

(b)

FIGURE 1: SEM micrographs of the Cu-poor/Zn-rich CZTS layers examined in this work after the etching procedure in aqueous $\mathrm{HCl}$ (300 sec at $75^{\circ} \mathrm{C}$ ): (a) plan view; (b) cross section.

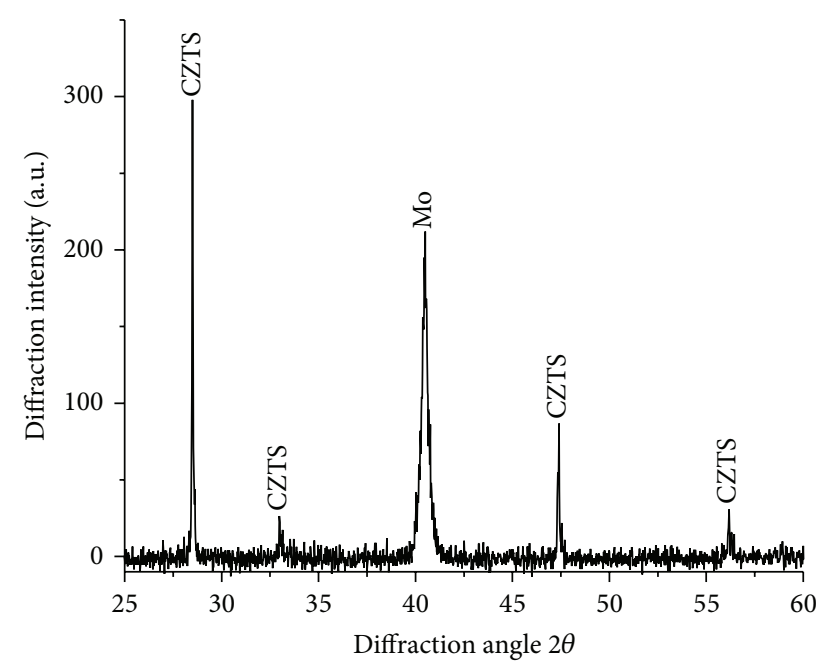

(a)

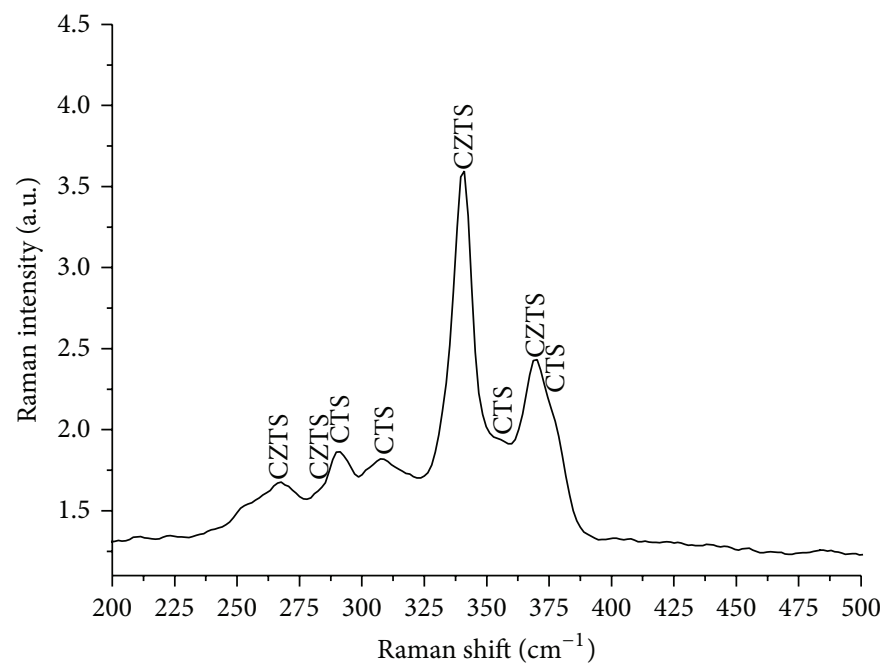

(b)

FIGURE 2: (a) XRD pattern and (b) Raman spectrum of the Cu-poor/Zn-rich CZTS layers examined in this work after the etching procedure in aqueous $\mathrm{HCl}$.

XRD analyses. The Raman spectrum reported in Figure 2(b) was observed in height uniformly distributed points of the as-grown CZTS layers etched with $\mathrm{HCl}$ [17], proving their in-plane homogeneity. The Raman spectrum reported in Figure 2(b) demonstrates as well the formation of $\mathrm{Cu}_{2} \mathrm{SnS}_{3}$ (CTS) as secondary phase. Along with the CZTS Raman modes at $267,287,338$, and $368 \mathrm{~cm}^{-1}$, the spectrum reported in Figure 2(b) shows in fact additional contributions at 290, 308,355 , and $377 \mathrm{~cm}^{-1}$, typical of cubic CTS [21]. Actually, secondary phases are likely to occur as a consequence of the rather small existence region of single phase CZTS [22], so the presence of CTS does not significantly decrease the CZTS layers quality. This is confirmed by both the shape and the maximum level of the EQE curve reported in Figure 3, which suggest better charge carrier generation and collection, compared to solar cells based on CZTS grown by other sputtering approaches $[16,19,23,24]$. The interpolation of the low energy side of the EQE curve shown in Figure 3 also allowed determining a $1.5 \mathrm{eV}$ bandgap for the CZTS absorber layers analyzed in this work (see the inset in Figure 3).

The effects of the above bandgap excitation process at low temperature on the photoluminescence of the as-grown CZTS samples etched with $\mathrm{HCl}$ [17] are depicted in Figure 4. In particular, PL spectra obtained for different excitation powers are shown, which roughly consist of a broad band centred around $1.21 \mathrm{eV}$, already observed in the literature [25]. 


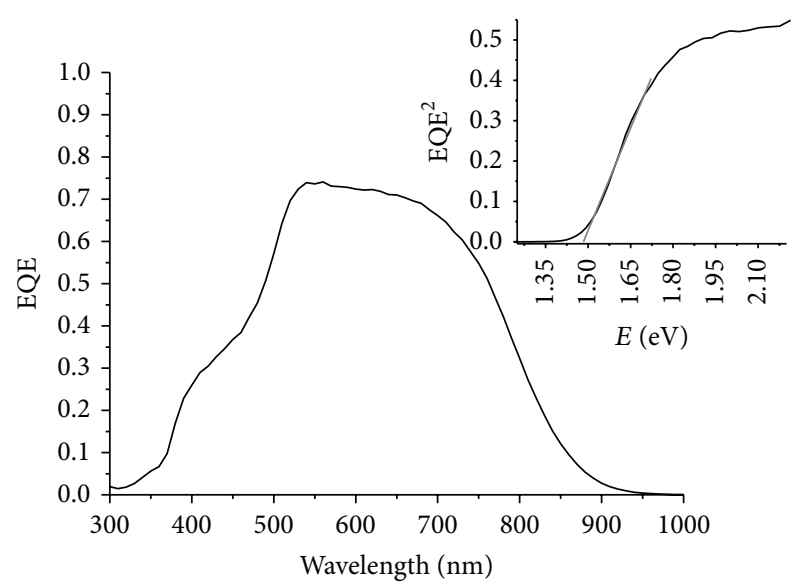

FIGURE 3: EQE of a CdS/CZTS solar cell based on the Cu-poor/Znrich CZTS layers examined in this work. The determination of the absorber bandgap obtained by interpolation of the low energy part of the EQE curve is reported in the inset.

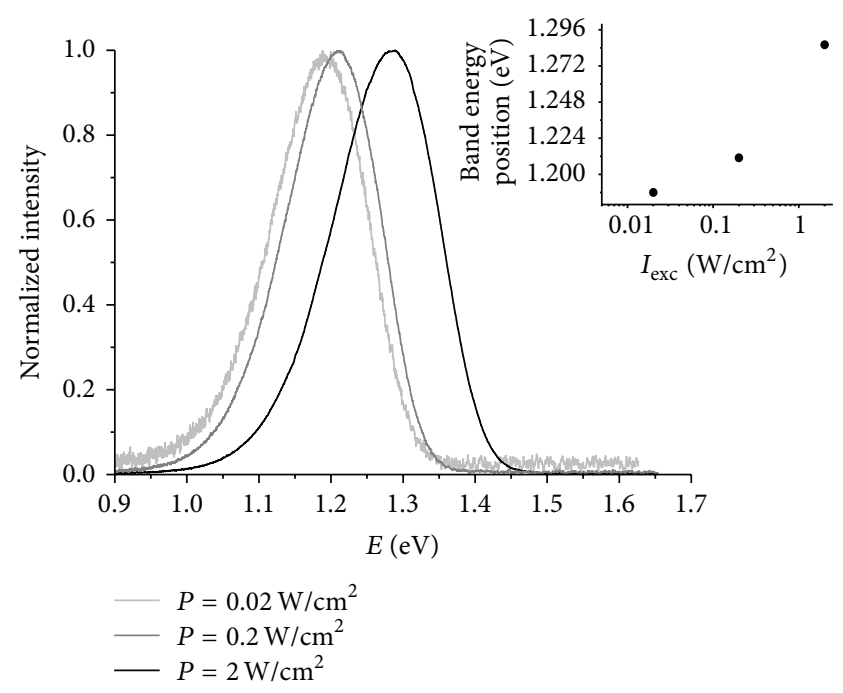

Figure 4: PL spectra at $20 \mathrm{~K}$ obtained for different excitation powers $\left(\lambda_{\text {exc }}=402 \mathrm{~nm}\right)$ on the as-grown CZTS samples after the etching procedure in aqueous $\mathrm{HCl}$. The band energy shift per decade of laser power of the emission at $1.21 \mathrm{eV}$ is reported in the inset.

This emission clearly exhibits a large blue shift for increasing excitation power (see Figure 4), typical of radiative recombinations known as quasi-donor-acceptor pair (QDAP) transitions, which involve potential fluctuations [26, 27]. This behaviour is well known in highly defective and compensated semiconductors like CIGS and CZTS [28, 29]. The QDAP band energy shift as a function of the excitation power is proportional to the depth of the potential fluctuations, resulting in shift per decade of laser power higher than $10 \mathrm{meV}$, as opposed to the $5 \mathrm{meV}$ per decade typical of donor-acceptor pair (DAP) transitions [30]. In good agreement with the literature [25], the inset in Figure 4 clearly demonstrates that the emission at $1.21 \mathrm{eV}$ shows an energy shift per decade of laser power definitely exceeding $10 \mathrm{meV}$, with higher slope in

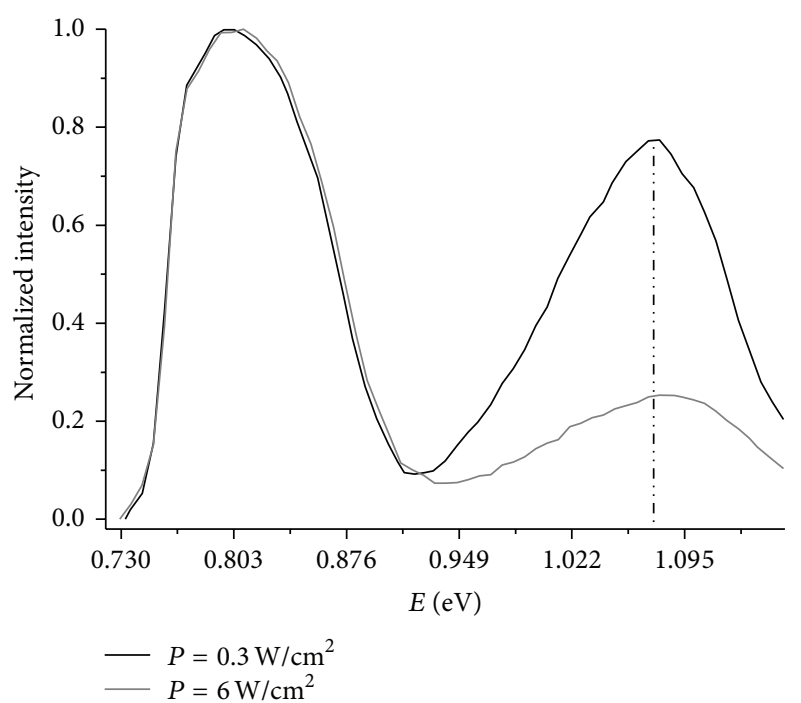

FIgURE 5: PL spectra at $20 \mathrm{~K}$ obtained for different excitation powers $\left(\lambda_{\text {exc }}=1064 \mathrm{~nm}\right)$ on the as-grown CZTS samples after the etching procedure in aqueous $\mathrm{HCl}$.

the high laser power region, as expected for QDAP [30]. Chen et al. argued that, in the case of $1.5 \mathrm{eV}$ CZTS bandgap, the $\mathrm{Cu}_{\mathrm{Zn}}$ acceptor level at $0.12 \mathrm{eV}$ above the VBM they calculated in [31] could be involved in the transition leading to this emission.

When both donors and acceptors are simultaneously present in the crystalline matrix, as in the case of compensated materials like CZTS, the acceptor's states are partially occupied and the donor's states are at least partially empty. Then, the absorption of photons with energy lower than the bandgap is possible by promoting electrons from occupied acceptor states to the conduction band. Such a below bandgap excitation produces an almost homogeneous distribution of nonequilibrium electrons over the entire sample thickness, which enables clearly detectable luminescence also due to the lower influence of nonradiative recombinations [32]. We observed luminescence from the as-grown CZTS samples etched with $\mathrm{HCl}$ [17] by exciting with a laser at $1064 \mathrm{~nm}$ (i.e., $1.165 \mathrm{eV}$ ), so an occupied acceptor level should be present at about $0.335 \mathrm{eV}$ from the VBM. This could explain the origin of the absorption process leading to the PL spectra reported in Figure 5, which shows two broad bands at 1.075 and $0.85 \mathrm{eV}$, respectively. However, due to the presence of a low bandgap secondary phase in the as-grown CZTS samples etched with $\mathrm{HCl}$ (i.e., CTS, see Figure 2(b)), further experiments are required to exclude that part of the spectrum in Figure 5 is associated with CTS-related contributions. In fact, the bandgap of cubic CTS is $0.96 \mathrm{eV}$ [33], so the excitation with a laser at $1064 \mathrm{~nm}$ (i.e., $1.165 \mathrm{eV}$ ) could give rise to above bandgap excited luminescence in CTS. In order to investigate this topic, CTS layers were grown by sulphurization at $500^{\circ} \mathrm{C}$ of stacked metal precursors with precursor sequence $\mathrm{SLG} / \mathrm{Mo} / \mathrm{Sn} / \mathrm{Zn}$, using the same experimental setup described in [15]. The Raman spectrum reported in Figure 6(a) confirms the formation of the desired 


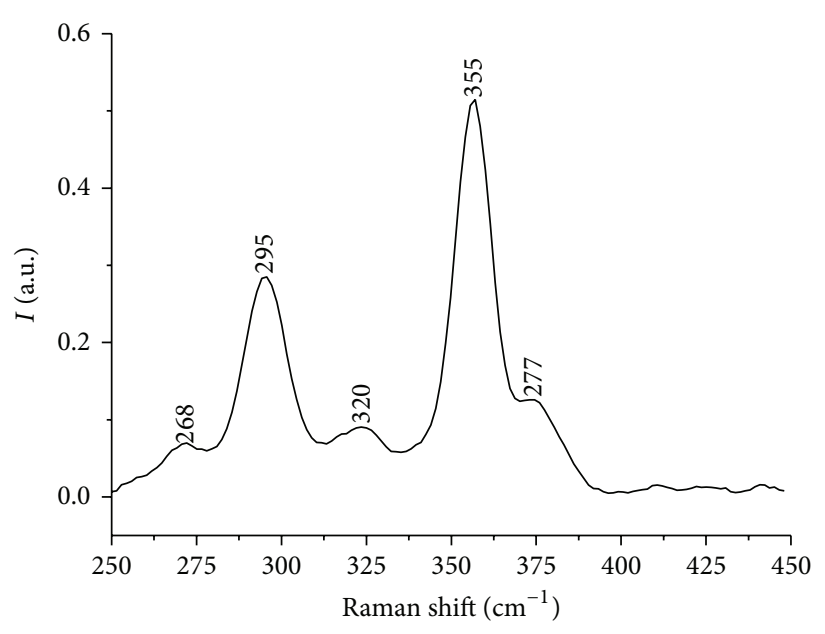

(a)

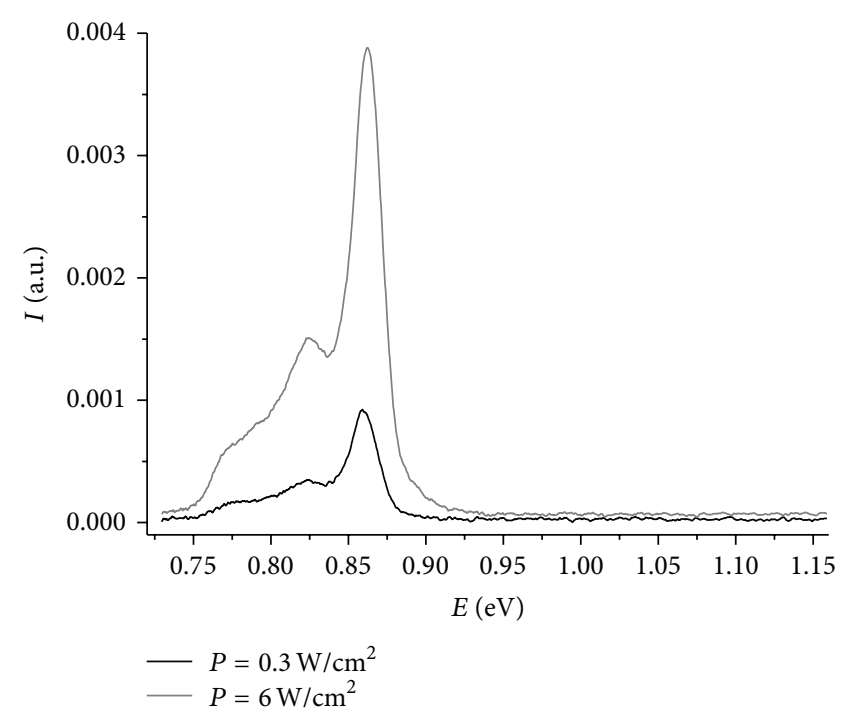

(b)

Figure 6: (a) Raman spectrum and (b) PL spectra at $20 \mathrm{~K}$ obtained for different excitation powers $\left(\lambda_{\text {exc }}=1064 \mathrm{~nm}\right)$ on the as-grown CTS samples.

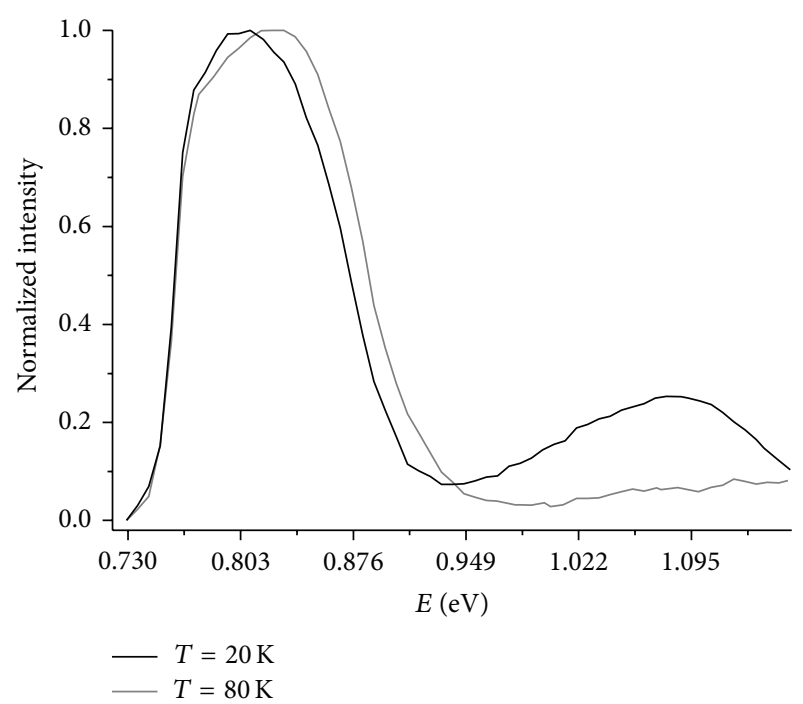

FIGURE 7: PL spectra obtained at different temperatures $\left(\lambda_{\mathrm{exc}}=\right.$ $\left.1064 \mathrm{~nm}, P_{\text {exc }}=6 \mathrm{~W} / \mathrm{cm}^{2}\right)$ on the as-grown CZTS samples after the etching procedure in aqueous $\mathrm{HCl}$.

cubic CTS phase [21]. The PL spectra obtained from CTS layers under $1064 \mathrm{~nm}$ excitation shown in Figure 6(b) prove that no correlation exists between the presence of CTS in the analyzed CZTS layers and the emissions depicted in Figure 5. In order to unravel the nature of the broad bands at 1.075 and $0.85 \mathrm{eV}, \mathrm{PL}$ spectra at different excitation powers and different temperatures were then performed. As shown in Figure 5, the former exhibits a limited blue shift with increasing excitation power, while the latter remains unaffected. Furthermore, Figure 7 demonstrates that, while the band at $0.85 \mathrm{eV}$ shows a blue shift for increasing temperature, the emission at
$1.075 \mathrm{eV}$ vanishes. The emission at $0.85 \mathrm{eV}$ exhibits therefore the typical behaviour of free-to-bound (FB) recombinations, while that at $1.075 \mathrm{eV}$ shows the typical characteristics of DAP transitions. Due to its energy position and FB nature, the emission at $0.85 \mathrm{eV}$ could be explained in terms of a transition between the conduction band and an empty deep level. Under below bandgap excitation conditions there is a relatively high probability that the processes of generation and recombination occur at the same defect, since the migration of electrons is limited due to the small kinetic energy that they obtain by the optical excitation. Therefore, the broad band at $1.075 \mathrm{eV}$ can be ascribed to a DAP recombination involving the above mentioned occupied acceptor level at about $0.335 \mathrm{eV}$ from the VBM and an empty donor level, which should be very shallow, considering that this emission vanishes around $70 \mathrm{~K}$. Taking into account the mean atomic concentrations of $\mathrm{Cu}, \mathrm{Zn}, \mathrm{Sn}$, and S typical of the examined CZTS samples, some hypotheses can be formulated on the point defects responsible for the observed emissions on the basis of the first-principles calculations performed by Chen et al. [31]. However, these theoretical data must be considered with care due to the occurrence of potential fluctuations in the examined samples, since in this case the transition energies are the average energies of the levels involved in the observed emissions. As far as the occupied acceptor level involved both in the absorption process of the $1064 \mathrm{~nm}$ radiation and in the emission at $1.075 \mathrm{eV}$ is concerned, three possible point defects can be considered, namely, $\mathrm{V}_{\mathrm{Sn}}, \mathrm{Cu}_{\mathrm{Sn}}$, and $\mathrm{Zn}_{\mathrm{Sn}}[31$. According to Chen's calculations [31], in Cu-poor conditions $\mathrm{Cu}_{\mathrm{Sn}}$ and $\mathrm{Zn}_{\mathrm{Sn}}$ have lower formation energies than those of $\mathrm{V}_{\mathrm{Sn}}$, so one of these antisite defects is probably involved in the absorption process of the $1064 \mathrm{~nm}$ radiation and in the emission at $1.075 \mathrm{eV}$. As far as the empty deep level involved in the radiative transition at $0.85 \mathrm{eV}$ is concerned, three possible point defects can be considered, namely, $\mathrm{V}_{\mathrm{S}}, \mathrm{Sn}_{\mathrm{Cu}}$, 


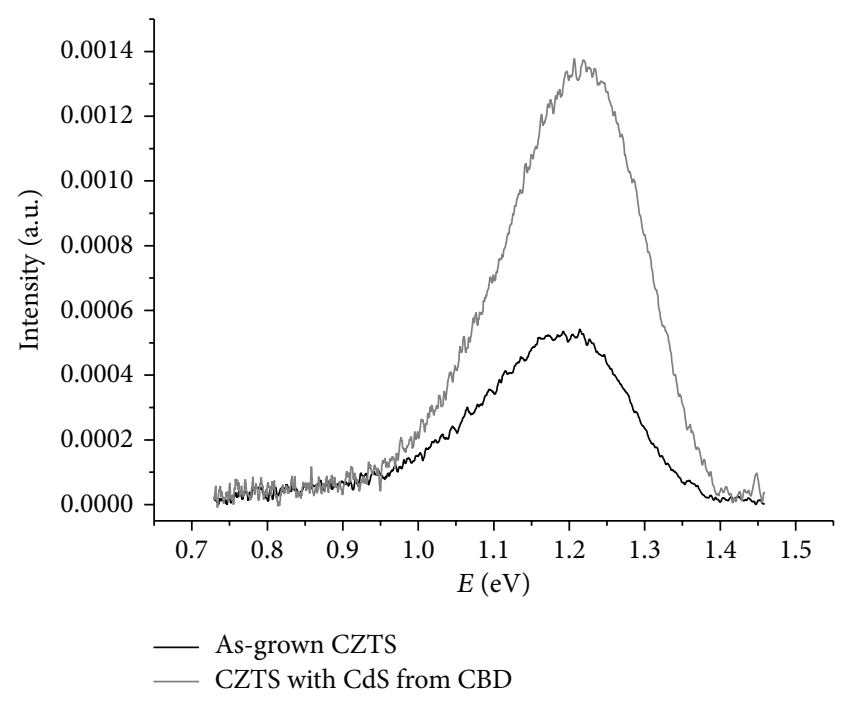

Figure 8: PL spectra at $300 \mathrm{~K}\left(\lambda_{\text {exc }}=402 \mathrm{~nm}, P_{\mathrm{exc}}=2 \mathrm{~W} / \mathrm{cm}^{2}\right)$ of the as-grown CZTS samples after the etching procedure in aqueous $\mathrm{HCl}$ (black line) and of CdS/CZTS solar cells (grey line).

and $\mathrm{Sn}_{\mathrm{i}}$ [31]. According to Chen's calculations [31], in Cu-poor conditions $\mathrm{Sn}_{\mathrm{Cu}}$ and $\mathrm{Sn}_{\mathrm{i}}$ have formation energies definitely higher than those of $\mathrm{V}_{S}$, so the latter can be involved in the emission at $0.85 \mathrm{eV}$.

Figure 8 shows the comparison between the PL spectra of CZTS excited with above bandgap radiation at room temperature before and after the chemical bath deposition of CdS. Although CZTS solar cells show luminescence intensity higher than the as-grown layers, it is apparent from Figure 8 that the same emission is present in both cases. This experimental evidence suggests that no passivation of the point defects involved in this emission by $\mathrm{Cd}$ atoms occurs at the CdS/CZTS interface as a consequence of the CBD process. Furthermore, many reasons can explain the increased PL intensity observed for CZTS solar cells: (a) change in the CZTS layer band bending due to the junction formation, which could tend to separate charges, thus altering the PL intensity; (b) decrease of nonradiative recombination paths associated with point defects or point defects complexes passivated by $\mathrm{Cd}$ atoms at the CdS/CZTS interface; (c) decrease of the surface recombination due to the passivation of dangling bonds by the formation of CdS buffer layer.

As far as below bandgap excitation at low temperature is concerned, accurate PL analyses showed that the emissions at 1.075 and $0.85 \mathrm{eV}$ both disappear in CZTS solar cells (see Figure 9), suggesting that the point defects involved in these emissions are instead passivated by $\mathrm{Cd}$ atoms at the CdS/CZTS interface during the CBD process. This seems to confirm the hypothesis formulated above on the point defect responsible for the emission at $1.075 \mathrm{eV}$ observed under below bandgap excitation. In fact, Maeda et al. [34] demonstrated that, during the CBD of CdS on the CZTS layer, $\mathrm{Cu}$ and $\mathrm{Zn}$ atoms dissolve in the aqueous solution, forming $\left[\mathrm{Cu}\left(\mathrm{NH}_{3}\right)_{2}\right]^{+}$ and $\left[\mathrm{Zn}\left(\mathrm{NH}_{3}\right)_{4}\right]^{2+}$ complex ions, respectively. Therefore, $\mathrm{Cd}$

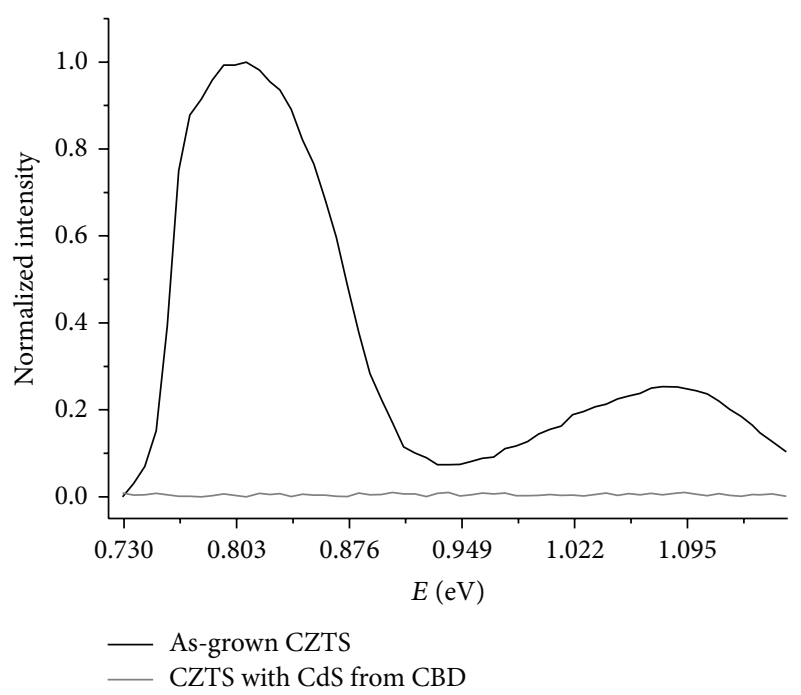

Figure 9: PL spectra at $20 \mathrm{~K}\left(\lambda_{\mathrm{exc}}=1064 \mathrm{~nm}, P_{\mathrm{exc}}=6 \mathrm{~W} / \mathrm{cm}^{2}\right)$ of the as-grown CZTS samples after the etching procedure in aqueous $\mathrm{HCl}$ (black line) and of CdS/CZTS solar cells (grey line).

atoms can more easily substitute for the $\mathrm{Cu}$ or $\mathrm{Zn}$ atoms in CZTS with respect to $\mathrm{Sn}$ atoms.

\section{Conclusions}

Point defect-related radiative recombinations in CZTS thin films with compositional ratios in the range associated with high efficiency devices were studied by photoluminescence before and after the chemical bath deposition of CdS in order to evaluate the possible passivation of point defects by $\mathrm{Cd}$ atoms at the CdS/CZTS interface. According to the literature, a broad emission around $1.21 \mathrm{eV}$ associated with a quasi-donor-acceptor pair transition was observed at low temperature under above bandgap excitation of the as-grown CZTS samples. Broad bands at $1.075 \mathrm{eV}$ and $0.85 \mathrm{eV}$ were detected for the first time under below bandgap excitation of the as-grown CZTS samples at low temperature, which were tentatively explained in terms of radiative transitions involving point defects related levels determined in the literature by first-principles calculations. The comparison between the spectral features of CZTS before and after the chemical bath deposition of CdS suggests, as in the case of CIGS, the occurrence of point defect passivation by $\mathrm{Cd}$ atoms at the CdS/CZTS interface, in agreement with literature firstprinciples studies. In spite of the fact that the optimization of alternative buffer layers for CZTS based PV is presently at a first stage, the occurrence of point defect passivation by $\mathrm{Cd}$ atoms at the CdS/CZTS interface which can be inferred from the presented results could explain the low efficiency so far obtained in the literature for CZTS solar devices with Cdfree buffer layers. Furthermore, the experimental evidences and hypotheses reported in this work can act as starting point for future investigations involving complementary characterization techniques, as for example SIMS. 


\section{Conflict of Interests}

The authors declare that there is no conflict of interests regarding the publication of this paper.

\section{Acknowledgment}

This work was partially supported by the executive programme of scientific and technological cooperation between Italy and Egypt through the joint research project PGR00116.

\section{References}

[1] M. A. Green, K. Emery, Y. Hishikawa, W. Warta, and E. D. Dunlop, "Solar cell efficiency tables (version 44)," Progress in Photovoltaics: Research and Applications, vol. 22, no. 7, pp. 701710, 2014.

[2] N. Naghavi, D. Abou-Ras, N. Allsop et al., Progress in Photovoltaics: Research and Applications, vol. 18, 2010.

[3] D. Liao and A. Rockett, "Cd doping at the CuinSe ${ }_{2} / \mathrm{CdS}$ heterojunction," Journal of Applied Physics, vol. 93, no. 11, pp. 93809382, 2003.

[4] T. Nakada and A. Kunioka, "Direct evidence of Cd diffusion into $\mathrm{Cu}(\mathrm{In}, \mathrm{Ga}) \mathrm{Se}_{2}$ thin films during chemical-bath deposition process of CdS films," Applied Physics Letters, vol. 74, no. 17, pp. 2444-2446, 1999.

[5] C. Heske, D. Eich, R. Fink et al., "Localization of Na impurities at the buried CdS/Cul(In, Ga)Se ${ }_{2}$ heterojunction," Applied Physics Letters, vol. 75, no. 14, pp. 2082-2084, 1999.

[6] A. Aquino and A. Rockett, "Chemical reactions at CdS heterojunctions with CuInSe $e_{2}$," Journal of Vacuum Science \& Technology A: Vacuum, Surfaces, and Films, vol. 31, no. 2, Article ID 021202, 2013.

[7] J. B. Varley and V. Lordi, "Intermixing at the absorber-buffer layer interface in thin-film solar cells: the electronic effects of point defects in $\mathrm{Cu}(\mathrm{In}, \mathrm{Ga})(\mathrm{Se}, \mathrm{S})_{2}$ and $\mathrm{Cu}_{2} \mathrm{ZnSn}(\mathrm{Se}, \mathrm{S})_{4}$ devices," Journal of Applied Physics, vol. 116, no. 6, Article ID 063505, 2014.

[8] J. Kim, C. Park, S. M. Pawar et al., "Optimization of sputtered $\mathrm{ZnS}$ buffer for $\mathrm{Cu}_{2} \mathrm{ZnSnS}_{4}$ thin film solar cells," Thin Solid Films, vol. 566, pp. 88-92, 2014.

[9] N. Sakai, H. Hiroi, and H. Sugimoto, "Development of Cd-free buffer layer for $\mathrm{Cu}_{2} \mathrm{ZnSnS}_{4}$ thin-film solar cells," in Proceedings of the 37th IEEE Photovoltaic Specialists Conference, pp. 003654003657, Seattle, Wash, USA, June 2011.

[10] T. Ericson, J. J. Scragg, A. Hultqvist et al., “ $\mathrm{Zn}(\mathrm{O}, \mathrm{S})$ Buffer layers and thickness variations of CDS buffer for $\mathrm{Cu} 2 \mathrm{ZnSnS4}$ solar cells," IEEE Journal of Photovoltaics, vol. 4, no. 1, pp. 465-469, 2014.

[11] J. Kim, H. Hiroi, T. K. Todorov et al., "High efficiency $\mathrm{Cu}_{2} \mathrm{ZnSn}(\mathrm{S}, \mathrm{Se})_{4}$ solar cells by applying a double $\mathrm{In}_{2} \mathrm{~S}_{3} / \mathrm{CdS}$ emitter," Advanced Materials, vol. 26, no. 44, pp. 7427-7431, 2014.

[12] C. Yan, F. Liu, N. Song et al., "Band alignments of different buffer layers (CdS, $\mathrm{Zn}(\mathrm{O}, \mathrm{S})$, and $\mathrm{In}_{2} \mathrm{~S}_{3}$ ) on $\mathrm{Cu}_{2} \mathrm{ZnSnS}_{4}$," Applied Physics Letters, vol. 104, no. 17, Article ID 173901, 2014.

[13] S. Shirakata, K. Ohkubo, Y. Ishii, and T. Nakada, "Effects of CdS buffer layers on photoluminescence properties of $\mathrm{Cu}(\mathrm{In}, \mathrm{Ga}) \mathrm{Se}_{2}$ solar cells," Solar Energy Materials \& Solar Cells, vol. 93, no. 6-7, pp. 988-992, 2009.
[14] S. Shirakata and T. Nakada, "Time-resolved photoluminescence in $\mathrm{Cu}(\mathrm{In}, \mathrm{Ga}) \mathrm{Se}_{2}$ thin films and solar cells," Thin Solid Films, vol. 515, no. 15, pp. 6151-6154, 2007.

[15] S. Marchionna, P. Garattini, A. Le Donne, M. Acciarri, S. Tombolato, and S. Binetti, " $\mathrm{Cu}_{2} \mathrm{ZnSnS}_{4}$ solar cells grown by sulphurisation of sputtered metal precursors," Thin Solid Films, vol. 542, pp. 114-118, 2013.

[16] C. Platzer-Björkman, J. Scragg, H. Flammersberger, T. Kubart, and M. Edoff, "Influence of precursor sulfur content on film formation and compositional changes in $\mathrm{Cu}_{2} \mathrm{ZnSnS}_{4}$ films and solar cells," Solar Energy Materials and Solar Cells, vol. 98, pp. 110-117, 2012.

[17] A. Fairbrother, E. García-Hemme, V. Izquierdo-Roca et al., "Development of a selective chemical Etch to improve the conversion efficiency of $\mathrm{Zn}$-rich $\mathrm{Cu}_{2} \mathrm{ZnSnS}_{4}$ solar cells," Journal of the American Chemical Society, vol. 134, no. 19, pp. 8018-8021, 2012.

[18] H. Araki, A. Mikaduki, Y. Kubo et al., "Preparation of $\mathrm{Cu}_{2} \mathrm{ZnSnS}_{4}$ thin films by sulfurization of stacked metallic layers," Thin Solid Films, vol. 517, no. 4, pp. 1457-1460, 2008.

[19] R. B. V. Chalapathy, G. S. Jung, and B. T. Ahn, "Fabrication of $\mathrm{Cu}_{2} \mathrm{ZnSnS}_{4}$ films by sulfurization of $\mathrm{Cu} / \mathrm{ZnSn} / \mathrm{Cu}$ precursor layers in sulfur atmosphere for solar cells," Solar Energy Materials and Solar Cells, vol. 95, no. 12, pp. 3216-3221, 2011.

[20] H. Katagiri, "Cu $\mathrm{ZnSnS}_{4}$ thin film solar cells," Thin Solid Films, vol. 480-481, pp. 426-432, 2005.

[21] A.-J. Cheng, M. Manno, A. Khare, C. Leighton, S. A. Campbell, and E. S. Aydil, "Imaging and phase identification of $\mathrm{Cu}_{2} \mathrm{ZnSnS}_{4}$ thin films using confocal Raman spectroscopy," Journal of Vacuum Science and Technology A: Vacuum, Surfaces and Films, vol. 29, no. 5, Article ID 051203, 2011.

[22] S. Chen, X. G. Gong, A. Walsh, and S.-H. Wei, "Crystal and electronic band structure of $\mathrm{Cu}_{2} \mathrm{ZnSnX}_{4}(\mathrm{X}=\mathrm{S}$ and Se) photovoltaic absorbers: first-principles insights," Applied Physics Letters, vol. 94, no. 4, Article ID 041903, 2009.

[23] P. A. Fernandes, P. M. P. Salomé, A. F. da Cunha, and B.-A. Schubert, " $\mathrm{Cu}_{2} \mathrm{ZnSnS}_{4}$ solar cells prepared with sulphurized dcsputtered stacked metallic precursors," Thin Solid Films, vol. 519, no. 21, pp. 7382-7385, 2011.

[24] N. Momose, M. T. Htay, T. Yudasaka et al., " $\mathrm{Cu}_{2} \mathrm{znsns}_{4}$ thin film solar cells utilizing sulfurization of metallic precursor prepared by simultaneous sputtering of metal targets," Japanese Journal of Applied Physics, vol. 50, no. 1, Article ID 01BG09, 2011.

[25] J. P. Leitão, N. M. Santos, P. A. Fernandes et al., "Study of optical and structural properties of $\mathrm{Cu}_{2} \mathrm{ZnSnS}_{4}$ thin films," Thin Solid Films, vol. 519, no. 21, pp. 7390-7393, 2011.

[26] P. W. Yu, "Excitation-dependent emission in Mg-, Be-, Cd-, and Zn-implanted GaAs," Journal of Applied Physics, vol. 48, no. 12, pp. 5043-5051, 1977.

[27] J. P. Leitão, N. M. Santos, P. A. Fernandes et al., "Photoluminescence and electrical study of fluctuating potentials in $\mathrm{Cu}_{2} \mathrm{ZnSnS}_{4}$-based thin films," Physical Review B, vol. 84, no. 2, Article ID 024120, 8 pages, 2011.

[28] M. J. Romero, H. Du, G. Teeter, Y. Yan, and M. M. AlJassim, "Comparative study of the luminescence and intrinsic point defects in the kesterite $\mathrm{Cu}_{2} \mathrm{ZnSnS}_{4}$ and chalcopyrite $\mathrm{Cu}(\mathrm{In}, \mathrm{Ga}) \mathrm{Se}_{2}$ thin films used in photovoltaic applications," Physical Review B, vol. 84, no. 16, Article ID 165324, 2011.

[29] T. Gershon, B. Shin, T. Gokmen, S. Lu, N. Bojarczuk, and S. Guha, "Relationship between $\mathrm{Cu}_{2} \mathrm{ZnSnS}_{4}$ quasi donor-acceptor pair density and solar cell efficiency," Applied Physics Letters, vol. 103, no. 19, Article ID 193903, 2013. 
[30] R. Bacewicz, P. Zuk, and R. Trykozko, "Photoluminescence study of $\mathrm{ZnO} / \mathrm{CdS} / \mathrm{Cu}(\mathrm{In}, \mathrm{Ga}) \mathrm{Se}_{2}$ solar cells," Opto-Electronics Review, vol. 11, no. 4, pp. 277-280, 2003.

[31] S. Chen, J.-H. Yang, X. G. Gong, A. Walsh, and S.-H. Wei, "Intrinsic point defects and complexes in the quaternary kesterite semiconductor $\mathrm{Cu}_{2} \mathrm{ZnSnS}_{4}$," Physical Review B, vol. 81, no. 24, Article ID 245204, 10 pages, 2010.

[32] J. I. Pankove, Optical Processes in Semiconductors, Dover Publications, New York, NY, USA, 1971.

[33] P. A. Fernandes, P. M. P. Salomé, and A. F. da Cunha, "A study of ternary $\mathrm{Cu}_{2} \mathrm{SnS}_{3}$ and $\mathrm{Cu}_{3} \mathrm{SnS}_{4}$ thin films prepared by sulfurizing stacked metal precursors," Journal of Physics D: Applied Physics, vol. 43, no. 21, Article ID 215403, 2010.

[34] T. Maeda, S. Nakamura, and T. Wada, "First-principles study on $\mathrm{Cd}$ Doping in $\mathrm{Cu}_{2} \mathrm{ZnSnS}_{4}$ and $\mathrm{Cu}_{2} \mathrm{ZnSnSe}_{4}$," Japanese Journal of Applied Physics, vol. 51, no. 10S, Article ID 10NC11, 2012. 